\title{
ESTUDO SOBRE O ENSINO SUPERIOR E A DEFICIÊNCIA AUDITIVA A PARTIR DO CONCEITO DE MEDIAÇÃO DE VYGOTSKY
}

\section{SURVEY ON HIGHER EDUCATION AND HEARING DISABILITY FROM THE VYGOTSKY MEDIATION CONCEPT}

DOI: http://dx.doi.org/10.5965/1984317813022017033

Bruna da Silveira Suris, André Luís Marques da Silveira, Heli Meurer - CENTRO UNIVERSITÁRIO

RITTER DOS REIS

\begin{abstract}
RESUMO
Este artigo apresenta um estudo que pretende ampliar o entendimento e disseminação da acessibilidade acadêmica por estudantes com deficiência auditiva. O objetivo deste estudo é analisar como ocorre e quem participa da inserção e inclusão do aluno surdo no Ensino Superior, a partir do conceito de mediação de Vygotsky. Para isso, realizou-se uma pesquisa de natureza básica, de caráter descritivo e com o procedimento técnico de coleta de dados, onde foi feita entrevista com tradutores e intérpretes de Libras. Na entrevista tratou-se da relação dos profissionais com os estudantes, seus anseios, suas principais demandas e a interação dos alunos com os colegas e professores. A execução consistiu na investigação em base de dados, a partir de material já publicado sobre o tema em questão. Com este trabalho pretende-se fomentar a pesquisa sobre os temas abordados e auxiliar na busca por novos estudos.
\end{abstract}

Palavras-chave: Ensino Superior. Acessibilidade. Deficiência Auditiva. Vygotsky.

\begin{abstract}
This article presents a study that intends to broaden the understanding and dissemination of academic accessibility by students with hearing impairment. The objective of this study is to analyze how it occurs and who participates in the insertion and inclusion of the deaf student in Higher Education, based on Vygotsky's concept of mediation. For this, was made a basic research, of a descriptive character and with the technical procedure of data collection, was carried out, where an interview was made with translators and interpreters of Libras. The interview was about the relationship of the professionals with the students, their desires, their main demands and the interaction of the students with their colleagues and teachers. The execution consisted in the investigation in database, from material already published on the subject in question. This work intends to promote research on the topics addressed and help in the search for new studies.
\end{abstract}

Keywords: Higher education. Accessibility. Hearing deficiency. Vygotsky. 


\section{INTRODUÇÃO}

Conforme Cartilha do Censo 2010 (2012), hoje 45.606 .048 brasileiros, ou seja, 23,9\% da população total do país possui pelo menos um tipo de deficiência. As pessoas com deficiência visual somam $8,60 \%$, já a população com deficiência auditiva $5,10 \%$, motora são $7 \%$ e mental ou intelectual $1,40 \%$. Como pode-se perceber as pessoas com deficiência auditiva totalizam um número bastante expressivo, sendo a segunda maior demanda, entre as cinco categorias.

Sabe-se que a educação é considerada, em nível global, o meio mais indicado para desenvolver o ser humano e a população no geral. Nesse sentido, se deve ter ciência de que toda e qualquer pessoa, deve ter direito ao estudo garantido, em decorrência do mesmo ser “inalienável e universal, sendo também considerado um direito que viabiliza a realização de outros direitos, pois ele prepara as pessoas com deficiência" (CARTILHA DO CENSO 2010, 2012 p.15).

Corrobora com o tema, a Declaração Universal dos Direitos Humanos (2009), adotada pela ONU em 1948. Ela dispõe no seu Artigo XXVI, que a educação é direito de toda a pessoa, sendo que ela deve ser obrigatória e gratuita pelo menos no ensino infantil, fundamental e médio. Com relação ao estudo superior, o acesso deverá ser aberto para toda a população de forma igualitária e em função do seu mérito.

Nota-se que a questão da acessibilidade e inclusão é uma temática social que necessita ser debatida, pois tornou-se desafiadora e indispensável para as organizações empresariais, escolas, órgãos públicos e também para as Instituições de Ensino Superior (IES) nos últimos anos. Em relação a isso, pode-se destacar algumas leis, decretos e requerimentos nessa área como a Convenção da ONU sobre o Direito das Pessoas com Deficiências de 2008, que serviu de base para a Lei 13.146/15 - Lei Brasileira da Inclusão, sancionada no ano de 2015.

Corrobora com a Lei 13.146/15 o Decreto 5.296/04 (regulamentador da Lei 10.048/00) que descreve (no seu capítulo III - Das condições gerais de acessibilidade) o desenho industrial como um termo utilizado para a concepção de espaços, artefatos e produtos que visam atender simultaneamente todas as pessoas, com diferentes características antropométricas e sensoriais, de forma autônoma, segura e confortável, constituindo-se nos elementos ou soluções que compõem a acessibilidade. 
Sendo assim, esta pesquisa tem por objetivo caracterizar como se dá o processo de mediação do aprendizado de alunos com deficiência auditiva e a sua inclusão e interação com os colegas e professores. Com isso, deseja-se fomentar pesquisas sobre o tema e demonstrar, dessa forma, a importância do entendimento e aplicação da acessibilidade nos cursos superiores no Brasil. Para isso, realizou-se uma coleta de dados por meio de entrevista via email, com o objetivo de reunir informações sobre a acessibilidade acadêmica, suas qualidades e necessidades de acordo com o conceito de mediação de Vygotsky. O problema de pesquisa deste artigo define-se da seguinte forma: Como se dá a aprendizagem de estudantes com deficiências auditivas no ensino superior de acordo com o conceito de mediação de Vygotsky?

\section{FUNDAMENTAÇÃO TEÓRICA}

A presente sessão divide-se da seguinte forma: Lei Brasileira da Inclusão da Pessoa com Deficiência; Acessibilidade, Design Universal e Tecnologia Assistiva; Língua Brasileira de Sinais e o Intérprete de Libras; Vygotsky e o conceito de mediação.

\subsection{Lei Brasileira da Inclusão da Pessoa com Deficiência}

Conforme o Guia sobre a Lei Brasileira da Inclusão (2015) a Lei Brasileira de Inclusão da Pessoa com Deficiência (Estatuto da Pessoa com Deficiência) - LBI 13.146, foi sancionada no dia 06 de Julho do ano de 2015, após 15 anos em tramitação. A trajetória da LBI se deu da seguinte forma: no ano de 2000 o texto foi apresentado pela primeira vez pelo deputado Paulo Paim e posteriormente, em 2003, uma nova proposta com teor idêntico, foi apresentada pelo então Senador Paulo Paim, ao Senado.

Houveram outras etapas, até que durante o processo, no ano de 2008, foi ratificada a Convenção da ONU sobre o Direito das Pessoas com Deficiências, o que trouxe um debate maior sobre o tema no país. Já entre os anos de 2013 a 2014 ocorreram consultas e audiências públicas abertas que recolheram sugestões da população de todo o Brasil sobre sugestões e propostas. No próprio ano de 2014 foi apresentado o texto final da LBI pela relatora Mara Gabrilli. Em 2015 houve a aprovação do texto na Câmara dos Deputados e aprovação no Senado, relatado pelo senador Romário, até que por fim ocorreu a sanção do projeto pela então Presidente Dilma Rousseff. (GUIA SOBRE A LEI BRASILEIRA DA INCLUSÃO, 
2015).

A LBI é destinada a assegurar e a promover, em condições de igualdade, o exercício dos direitos e das liberdades fundamentais da pessoa com deficiência, visando à sua inclusão social e cidadania. O texto da LBI tem como base fundamental a Convenção da ONU sobre os Direitos das Pessoas com Deficiência, sendo, o primeiro tratado internacional de direitos humanos a ser incorporado pelo ordenamento jurídico brasileiro como emenda constitucional. No Brasil, a LBI, baseou-se na carência de serviços públicos existentes e nas demandas da população como um todo. A sua composição partiu-se do pressuposto, de que, nenhum retrocesso sobre os direitos até então conquistados, poderia ser feito. (GUIA SOBRE A LEI BRASILEIRA DA INCLUSÃO, 2015).

Conforme o Guia sobre a Lei Brasileira da Inclusão (2015), no Art. 77 foi definido que o poder público deve fomentar o desenvolvimento científico, a pesquisa, a inovação e a capacitação tecnológica, voltada à melhoria da qualidade de vida e ao trabalho da pessoa com deficiência e sua inclusão social. O fomento pelo poder público deve priorizar a geração de conhecimentos e técnicas que visem à prevenção, o tratamento de deficiências e o desenvolvimento de tecnologias assistivas e sociais. A acessibilidade e as tecnologias assistivas e sociais devem ser fomentadas mediante a criação de cursos de pós-graduação, a formação de recursos humanos e a inclusão do tema nas diretrizes de áreas do conhecimento. Deve ser fomentada a capacitação tecnológica de instituições públicas e privadas para o desenvolvimento de tecnologias assistiva e social que sejam voltadas para melhoria da funcionalidade e da participação social da pessoa com deficiência. As medidas previstas neste artigo devem ser reavaliadas periodicamente pelo poder público, com vistas ao seu aperfeiçoamento.

Na LBI em seu Art. $3^{\circ}$ Para fins de aplicação da Lei, consideram-se alguns termos da seguinte maneira: I - acessibilidade: possibilidade e condição de alcance para utilização, com segurança e autonomia, de espaços, mobiliários, equipamentos urbanos, edificações, transportes, informação e comunicação, inclusive seus sistemas e tecnologias, bem como de outros serviços e instalações abertos ao público, de uso público ou privados de uso coletivo, tanto na zona urbana como na rural, por pessoa com deficiência ou com mobilidade reduzida; II - desenho universal: concepção de produtos, ambientes, programas e serviços a serem usados por todas as pessoas, sem necessidade de adaptação ou de projeto específico, incluindo 
os recursos de tecnologia assistiva; III - tecnologia assistiva ou ajuda técnica: produtos, equipamentos, dispositivos, recursos, metodologias, estratégias, práticas e serviços que objetivem promover a funcionalidade, relacionada à atividade e à participação da pessoa com deficiência ou com mobilidade reduzida, visando à sua autonomia, independência, qualidade de vida e inclusão social. (GUIA SOBRE A LEI BRASILEIRA DA INCLUSÃO, 2015).

\subsection{Acessibilidade, Design Universal e Tecnologia Assistiva}

Dessa forma, buscou-se entender o conceito dos termos acessibilidade, design universal e tecnologia assistiva para complementar a definição da LBI. Assim, o termo acessibilidade define que toda pessoa com deficiência e/ou mobilidade reduzida tenha possibilidade e condições, com segurança e autonomia, de utilizar espaços mobiliários, urbanos, de edificações, de transportes e de sistemas de comunicação. (BRASIL, 2000; LAMÔNICA et al., 2008).

Em decorrência da legislação brasileira, toda pessoa, incluindo as que apresentam deficiências, devem ter acesso garantido, à educação, à saúde, ao lazer e também ao trabalho. Andrade et al. (2007) corroboram com essa afirmação, pois, descrevem que todos os indivíduos devem ser percebidos com igualdade e com isso, devem receber atendimento e reconhecimento das suas necessidades.

Conforme Lamônica et al. (2008), ao serem assegurados por lei, às pessoas com deficiências têm seus direitos conquistados, e os mesmos necessitam ser respeitados, pois, a acessibilidade defende o conceito de cidadania. Porém, conforme, Bittencourt et al. (2004) as barreiras sociais e também as arquitetônicas dificultam a utilização plena destes direitos, pois, somente um espaço construído desde a sua concepção de modo acessível a todos, pode proporcionar oportunidades iguais aos seus usuários. Assim, refletir sobre as barreiras físicas que causam dificuldades as pessoas com deficiências são de extrema importância. Assim, o ideal é repensar práticas e propostas de ações que podem melhorar a qualidade de vida e promover a saúde destas pessoas.

Além do conceito de acessibilidade, também se faz necessário compreender o conceito de design universal. Cunhado em 1987, pelo arquiteto norte-americano Ron Mace, o termo tem crescido e com isso, gerado interesse, entre profissionais como designers, engenheiros, 
arquitetos, paisagistas, entre outros. O design universal tem sido aplicado em projetos de ambientes públicos, edifícios e produtos, sempre com o objetivo de produzir artefatos ou serviços, dos quais, a grande maioria das pessoas possa fazer uso.

A sua aplicação está diretamente ligada com uma sociedade inclusiva, pois não é apenas uma tecnologia focada aos que dela necessitam e sim um design para todas as pessoas. E envolve até mesmo questões ambientais, pois, o profissional que faz uso do design universal evita a necessidade de ambientes e produtos diferentes para pessoas com e sem deficiências, e ainda assegura que todos possam usar de forma segura e autônoma os espaços e objetos desenvolvidos. (CARLETTO; CAMBIAGHI, 2008).

Segundo Carletto e Cambiaghi (2008) em 1997 foram desenvolvidos os sete princípios do design universal por peritos do Centro de Desenho Universal da Universidade da Carolina do Norte, tendo como foco a concepção, no maior nível possível, de produtos e ambientes utilizáveis por todos os indivíduos sem necessidade de adaptações. O projeto universal pode ser aplicado tanto na avaliação de artefatos que já foram desenvolvidos, como servir de orientação para a criação de produtos e ambientes novos (IIDA, 2005).

Conforme Iida (2005) os sete princípios adotados no design universal são: Uso Equitativo, ser útil para pessoas com as mais diversas capacidades; Flexibilidade no uso, acomodar um grande leque de capacidades e preferências individuais; Uso Simples \& Intuitivo, tornar a utilização de produtos e ambientes de fácil entendimento, independente, da experiência de uso de cada pessoa; Informação Perceptível, tornar a comunicação do produto eficaz; Tolerância ao erro, reduzir ao máximo os riscos e consequências adversas das ações dos usuários; Redução do Gasto Energético, uso dos artefatos de forma eficiente e confortável com o mínimo possível de esforço; Espaço Apropriado, proporcionar tamanho e espaço apropriado ao uso independente do corpo, postura ou limitação do usuário.

Outro conceito de grande relevância para a área inclusiva é a tecnologia assistiva, que ao contrário do design universal, tem foco no desenvolvimento de projetos direcionados especificamente para crianças e/ou adultos com deficiências e/ou limitações. A tecnologia assistiva tem como objetivo propiciar as pessoas com deficiências e/ou limitações, recursos e serviços que proporcionem maior qualidade de vida, que atendam às suas necessidades e que ao mesmo tempo auxiliem na reabilitação, tornando-se assim, uma grande aliada, 
principalmente, para os profissionais da saúde. Assim, promover uma vida com independência e inclusão na sociedade é a prioridade. (BERSCH, 2016).

Citando o conceito do ADA - American with Disabilities Act, tecnologia assistiva refere-se a "uma ampla gama de equipamentos, serviços, estratégias e práticas concebidas e aplicadas para minimizar os problemas funcionais encontrados pelos indivíduos com deficiências”. É uma área voltada totalmente para o usuário e não um recurso do profissional ou de algum campo de trabalho de atuação específica e está diretamente interligada em diversas outras áreas, tornando-se um tema transdisciplinar, envolvendo diversos profissionais como educadores, engenheiros, arquitetos, designers, terapeutas ocupacionais, fonoaudiólogos, fisioterapeutas, médicos, assistentes sociais, psicólogos, entre outros. (COOK; HUSSEY, 1995).

Com relação ao aprendizado/ensino das pessoas com deficiências auditivas, segundo Bersch (2013) os produtos desenvolvidos na área da tecnologia assistiva são categorizados conforme sua funcionalidade, dividindo-se em doze. Para as pessoas com deficiência auditiva a categoria "Auxílios para pessoas com surdez ou com déficit auditivo" é a principal. Nela incluem-se uma variedade de equipamentos para facilitar a audição como: aparelhos para surdez, telefones com teclado-teletipo (TTY), sistemas com alerta táctil-visual, celular com mensagens escritas e chamadas por vibração, software que favorece a comunicação ao telefone celular transformando em voz o texto digitado no celular e em texto a mensagem falada.

Também há livros, textos e dicionários digitais em língua de sinais. Sistema de legendas, entre outros. Quanto aos materiais adaptados para o ensino em universidades, existem também produtos de tecnologia assistiva específicos, como por exemplo no Incluir Núcleo de Inclusão e Acessibilidade da UFRGS, sendo eles: Ledor e transcritor; Materiais didáticos em Braille, áudio, ampliado e táteis; Guia vidente; Softwares ledores e ampliadores de tela; Lupas eletrônicas, entre outros. (INCLUIR - NÚCLEO DE INCLUSÃO E ACESSIBILIDADE, 2016).

\subsection{Deficiência Auditiva e a Língua Brasileira de Sinais}

Seguindo o estudo nas áreas da inclusão com conceitos de acessibilidade, design 
universal e tecnologia assistiva, realizou-se também um levantamento bibliográfico sobre a deficiência auditiva e a Língua Brasileira de Sinais, pois entende-se que as pessoas com deficiências, sendo ela qual for, necessitam de espaços, produtos e serviços acessíveis, para desenvolverem plenamente suas capacidades. Corrobora Cambiaghi (2007 p.23) ao afirmar que "quando uma pessoa com deficiência está em um ambiente acessível, suas atividades são preservadas, e a deficiência não afeta suas funções".

Conforme o Decreto $\mathrm{n}^{\mathrm{o}} 5.296$ (2004), os tipos de deficiências existentes são: deficiência física, deficiência visual, deficiência mental, deficiência múltipla e deficiência auditiva. Assim, considera-se pessoa com deficiência auditiva, aquela que possui perda bilateral, parcial ou total, de 41 decibéis $(\mathrm{dB})$ ou mais, aferida por audiograma nas frequências de $500 \mathrm{~Hz}, 1000 \mathrm{~Hz}, 2000 \mathrm{~Hz}$ e $3000 \mathrm{~Hz}$.

No Brasil houve um aumento expressivo no número de pessoas com deficiências, se compararmos o ano 2000 com 2010, como se pode verificar na Figura 01. Em 2000, as pessoas com pelo menos um tipo de deficiência somavam 54\% com idade superior ou igual a 65 anos de idade, já no ano 2010 esse número aumentou para 67,7\%. Para a população com idade entre 15 a 64 anos, foco desta pesquisa por se tratar de pessoas ativas na sociedade quanto à educação, em 2000 totalizavam 15,6\% e em 2010 24,9\%. Já crianças entre 0 a 14 anos em 2000 eram 4,3\% e em 2010 passaram para 7,5\%. (CARTILHA DO CENSO 2010 PESSOAS COM DEFICIÊNCIAS, 2012).

Figura 01 - Pessoas com pelo menos uma deficiência nos anos 2000 e 2010

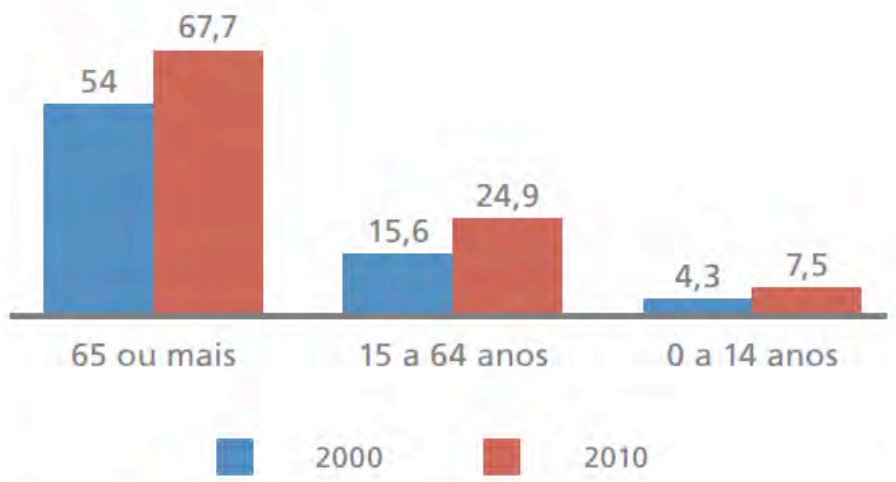

Fonte: Cartilha do Censo 2010 - Pessoas com Deficiências, 2012. 
A partir dos dados expostos, fica evidente que a preocupação com as pessoas com deficiências em fase de aprendizado, com idade entre 15 a 64 anos, deve ser debatida e estudada. Mas, sabe-se que conforme Cambiaghi (2007), a conquista da cidadania plena pelas pessoas com deficiências ainda está longe de ser alcançada, pois, sabe-se que a inclusão é um tema que engloba uma amplitude grande de questões e trata, acima de tudo, de uma mudança de olhar.

Assim, também se verificou a distribuição da população, acima de 15 anos, com pelo menos alguma deficiência em relação ao seu nível de instrução. O resultado encontrado foi que apenas $6,7 \%$ das pessoas com deficiências se enquadraram na categoria "Superior completo", já em relação as pessoas sem deficiências esse número sobe para 10,4\% (Figura 02). Ao observar esses números, pode-se identificar que as pessoas com deficiências com Ensino Superior completo, ainda são bem inferiores às pessoas sem deficiências. (CARTILHA DO CENSO 2010 - PESSOAS COM DEFICIÊNCIAS, 2012).

Figura 02 - População com mais de 15 anos e nível de instrução

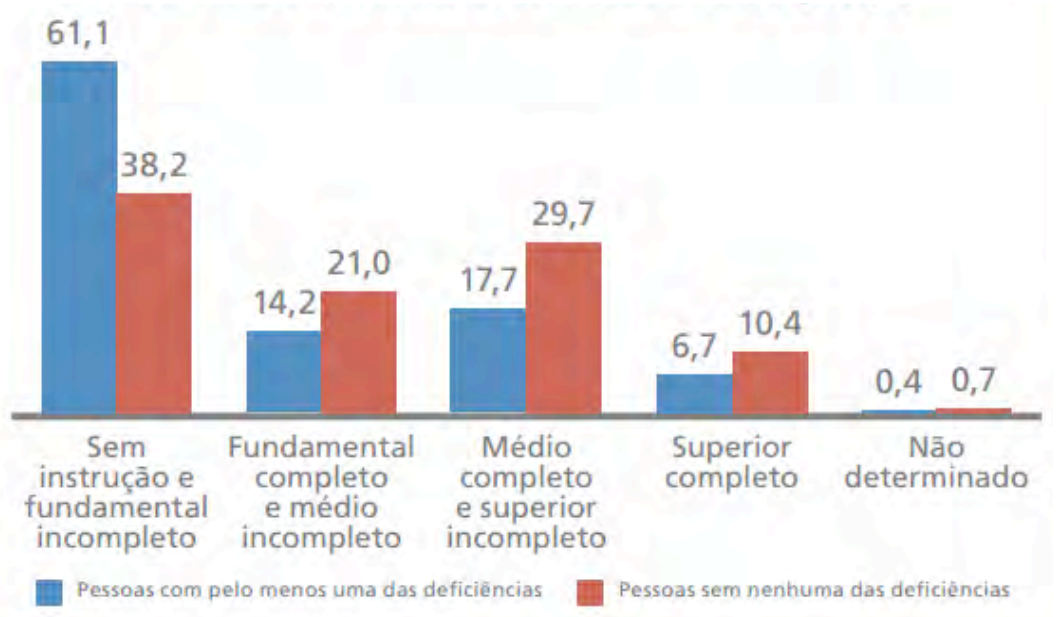

Fonte: Cartilha do Censo 2010 - Pessoas com Deficiências, 2012.

A partir dos dados obtidos, pode-se notar que no Brasil há um número bastante expressivo da população que tem pelo menos uma deficiência e que precisa ser percebida. Com relação a educação, as pessoas com deficiências também são prejudicadas e neste estudo irá se tratar, de forma mais abrangente, das pessoas com deficiências auditivas e o Ensino Superior. Conforme Sá (2006, p.16), os surdos são pessoas ditas “como deficientes e 
incapazes, desapropriadas de seus direitos e da possibilidade de escolhas". Conforme percebido é urgente e necessária uma mudança de pensamento a respeito da definição da surdez e dos surdos, por isso, deve-se incluir discussões sobre o tema nas Instituições de Ensino de todas as ordens, conforme corrobora Silva:

Se não é mais a pessoa surda ou a pessoa com incapacitação que é o problema, mas sim o discurso sobre a surdez e sobre a incapacitação, então, o que deve ser principalmente afetado é a educação e o currículo das pessoas "normais". Nesse espírito, são principalmente essas que devem ser educadas. (SILVA 1997, p.15)

Para que um estudante com deficiência auditiva possa ter um aprendizado presencial em uma Instituição de Ensino são necessárias algumas adaptações, mas principalmente, entra em cena a Língua Brasileira de Sinais - Libras, reconhecida como meio legal de comunicação e expressão conforme, Lei 10.436 (2002).

Com relação ao aprendizado por meio da Libras e o ensino, Taille et al (1992) afirmam que "enquanto sujeito de conhecimento o homem não tem acesso direto aos objetos, mas um acesso mediado". Esse é o contexto central para compreender Vygotsky, quanto ao processo de desenvolvimento humano e a ideia de mediação. Nesse âmbito, define-se por meio de Quadros (2004) que a Língua brasileira de Sinais é "língua visual-espacial articulada através das mãos, das expressões faciais e do corpo, sendo uma língua natural usada pela comunidade surda brasileira".

A presença de tradutores e intérpretes de Libras, professores bilíngues e de profissionais surdos (professores ou demais funcionários) são de extrema importância em um ambiente escolar apropriado para estudantes com deficiência auditiva. Assim, o tradutor e intérprete de Libras tem uma posição muito importante na interação entre o estudante com deficiência auditiva, os professores, os colegas e os funcionários, conforme descreve a autora Sá:

Os surdos [...] devem ser reconhecidos como uma minoria linguística, com o direito específico de ter suas línguas de sinais nativas aceitas como sua primeira língua 
oficial e como o meio de comunicação e instrução, tendo serviços de intérpretes para suas línguas de sinais. (SÁ 2006, p.91)

Para se tornar um tradutor e intérprete de Libras é necessária formação específica no Brasil e no mundo. Conforme Quadros (2004) o profissional poderá ter desde o nível secundário até mesmo o Mestrado, quanto mais alto o grau de ensino mais qualificado será o profissional. Assim, esse profissional torna-se indispensável para que ocorra a interação da comunidade surda e com isso uma participação ativa na sociedade em que as pessoas com deficiência auditiva estão inseridas.

Em determinados Estados brasileiros, houve a necessidade de criação de uma regulamentação da profissão. No Rio Grande do Sul os primeiros profissionais começaram suas capacitações no ano de 1997, por meio de cursos certificados pela FENEIS/RS e UFRGS. Assim, foi criado o regulamento estadual para atuação como tradutor e intérprete de Libras elaborados pelos próprios intérpretes do RS. (QUADROS, 2004)

Conforme o regulamento dos intérpretes da FENEIS-RS, o "intérprete é o profissional capaz de possibilitar comunicação entre surdos e ouvintes através da Libras para o português e vice-versa; ou entre outras línguas de sinais e línguas orais". O objetivo deste regulamento é propiciar às pessoas com deficiências auditivas o processo de tradução e interpretação com qualidade e ética. (QUADROS, 2004)

Diante do exposto pode-se perceber que a comunicação e a linguagem são extremamente necessárias na relação entre os seres humanos, conforme Taille (1992, p.27) “além de servir ao propósito de comunicação entre indivíduos, a linguagem simplifica e generaliza a experiência, ordenando as instâncias do mundo real em categorias conceituais cujo significado é compartilhado pelos usuários dessa linguagem”.

Para um estudante com deficiência auditiva o intérprete em Libras se torna essencial na interação com o conteúdo e assimilação do conhecimento em sala de aula. Conforme Silveira (2016), "através da mediação do professor, o sujeito internaliza conceitos externos, num processo de formação das funções psíquicas superiores". No caso do estudante com deficiência auditiva, essa mediação ocorre de maneira diferenciada, pois o professor explica o 
conteúdo, o intérprete em Libras o compreende e então faz a mediação entre o conhecimento e o aluno.

Sobre a situação brasileira do aluno com deficiência e a sua relação com o português escrito na Universidade, uma pesquisa realizada por profissionais da PUC do Paraná em convênio com o CENESP (Centro Nacional de Educação Especial) publicada em 1986 averiguou que "o Brasil tem aproximadamente $5 \%$ da população com deficiência auditiva total estudando em universidades e a maioria é incapaz de lidar com o português escrito". (FENEIS, 1995, p.07)

Atualmente, ainda são poucas as pessoas com deficiências auditivas nas Universidades, mas esse número tende a crescer ao longo dos anos. Para isso, é preciso que os professores desses alunos levem em consideração suas limitações, mas também os incentivando, tornando o estudo uma ferramenta de auxílio, como por exemplo na questão da leitura e escrita. Conforme Friães e Pereira (2000, p.121-122) “...o argumento de que o aluno surdo tem muita dificuldade de ler faz com que os professores evitem a atividade e, assim, a leitura vai-se tornando cada vez mais difícil, limitando-se a textos pequenos, facilitados". Segundo Lopes:

Estamos atravessados por uma lógica ouvintista que vem guiando nossas práticas e encaminhando a militância que fazemos na área a educação de surdos para uma simples exaltação das diferenças daqueles que, quando estão na escola, não acreditamos que possam aprender como "os outros". (LOPES, 2006, p.32)

Conforme Demo (2011) o professor deve identificar e conhecer as motivações e o contexto cultural de cada aluno, interessando-se por ele e estabelecendo uma relação de confiança e tranquilidade, aprendendo junto de forma participativa. Dessa forma, nota-se que o professor é um dos instrumentos que favorecem o desenvolvimento do aluno, em conjunto com os demais colegas e até mesmo demais alunos surdos. Assim, também é necessário compreender sobre o conceito de bilinguismo, que segundo Lopes (2007) objetiva a Libras como primeira língua dos surdos (aprendido o mais cedo possível pela criança) e o português como segunda língua (ensinada principalmente no modo escrito). 
Nesse momento percebe-se a importância fundamental do professor em sala de aula e também o quanto é necessário que ele se envolva na realidade do aluno surdo, em questões psicossociais, culturais e linguísticas, buscando formas adequadas para as metodologias de ensino bilingue, pois o entendimento do que é ser surdo para o professor é definitivo durante esse processo e também deve ser claro para os demais integrantes da comunidade acadêmica. (QUADROS, 1997)

Assim, o professor no papel de mediador entre o saber e o aluno, deve estar atento aos alunos surdos em relação aos aspectos cognitivos, para definir a melhor forma de transmitir a comunicação pedagógica; já ao tradutor e intérprete de Libras, cabe intermediar essa comunicação, ao traduzir de forma simultânea os conteúdos desenvolvidos e mediados pelo professor. Com isso, entender a respeito do conceito de mediação, sob o olhar de Vygotsky faz-se necessário.

\subsection{Vygotsky e o conceito de mediação}

Entende-se que a escola/universidade é o local de acesso dos estudantes ao conhecimento e que essa forma de aprender está sempre em evolução, sendo assim, para Zanella (2007, p.95) "o principal fator de desenvolvimento, portanto, consiste na apropriação, pelo sujeito, de novas formas de mediação, de novos signos, o que faz atribuir um papel de destaque à escolarização".

Sabe-se que o estudante ao longo do seu percurso acadêmico, participa de uma diversidade de relações e que as mesmas promovem a sua formação e desenvolvem suas funções psicológicas e que a partir dessas interações, que se dá o desenvolvimento humano e a apropriação das significações, que ressalta a "gênese social da consciência humana que Vygotsky defendia”. (ZANELLA, 2007).

Porém, percebe-se que conforme Zanella (2007, p. 102) “está implícita a noção de que a apropriação do conhecimento não se dá de forma passiva, visto implicar transformação de conteúdo ensinado e, portanto, do próprio sujeito que deste se apropria”. Para entender melhor esse conceito, pesquisou-se e foram identificadas as zonas de desenvolvimento, que segundo Silveira (2016), são: Zona de Desenvolvimento Real - o que o sujeito já aprendeu; Zona de 
Desenvolvimento Potencial - é o que o sujeito tem capacidade de aprender; Zona de Desenvolvimento Proximal - é o que o sujeito vai aprender sob a supervisão de outro sujeito.

A Zona de Desenvolvimento Proximal (ZDP) se caracteriza por um espaço social de interação, trocas múltiplas e de naturezas diversas. Na ZDP não acontece o desenvolvimento, sem a intervenção do outro, pois a aprendizagem se dá por mediação do outro, onde o aluno internaliza conceitos externos em processo de formação de suas funções psíquicas superiores (Figura 03). A ZDP, conforme Zanella (2007) não deve caracterizar-se apenas sendo do sujeito que aprende ou mesmo do ensino, mas também do sujeito envolvido na atividade colaborativa em contexto social e específico.

Figura 03 - Zona de Desenvolvimento Proximal

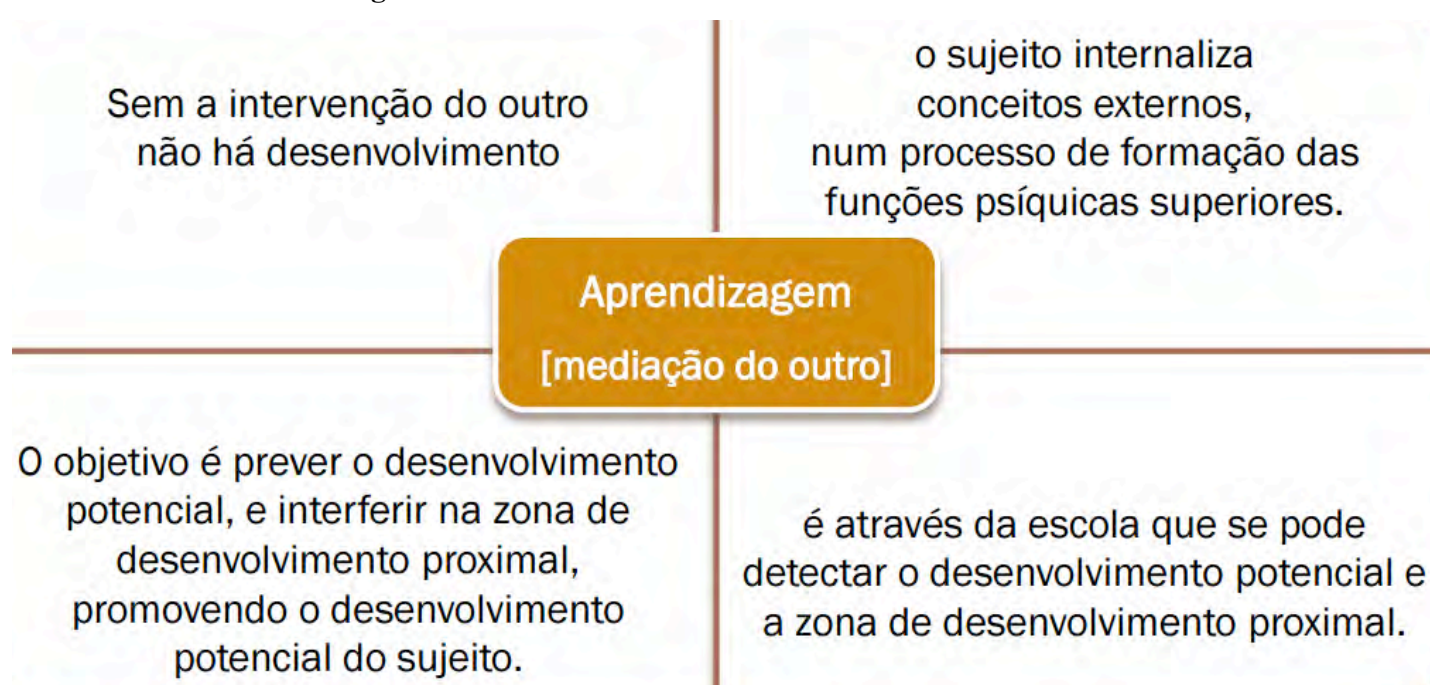

Fonte: Silveira, 2016.

Conforme Silveira (2016), há ferramentas de natureza material (física) ou representacional (signos) que são categorias de mediação. Elas possibilitam as funções psicológicas superiores do mesmo modo da linguagem. A linguagem envolve a relação do homem consigo e com os outros no meio social em interação recíproca com o meio físico. Conclui-se dessa maneira, que para que o aluno com deficiência auditiva possa concretizar sua aprendizagem no Ensino Superior, o mesmo necessita dessa mediação com outros atores, mas, principalmente no caso deste estudo, com o tradutor e intérprete de Libras. 


\section{METODOLOGIA}

O presente trabalho tem como objetivo principal realizar um levantamento teórico da acessibilidade acadêmica no Ensino Superior, no que diz respeito aos estudantes com deficiência auditiva e o seu aprendizado. Para isso, é válido destacar à metodologia científica e a sua relevância para os estudos acadêmicos.

Assim, sob o ponto de vista da natureza esta pesquisa é básica e tem como foco desenvolver conhecimentos novos e úteis para a ampliação da ciência, envolvendo verdades e interesses sociais. Quanto aos seus objetivos é uma pesquisa de caráter descritivo, que segundo Sampieri; Collado; Lucio (2013) tem como foco especificar propriedades de objetos ou fenômenos nos quais podemos analisar, descrevendo informações de forma independente, não sendo necessário relacionar conceitos e variáveis. $\mathrm{O}$ procedimento técnico adotado com relação ao método é de pesquisa de coleta de dados, na qual primeiramente se realiza um levantamento bibliográfico, onde será realizado o estudo de materiais já publicados sobre a temática pesquisada através de livros, periódicos, anais de eventos, entre outros.

A coleta de dados em um estudo pode envolver o tipo de coleta de dados a partir de Entrevistas, conforme Creswell (2010). O método de entrevista (nessa pesquisa realizado por e-mail) foi escolhido porque uma das entrevistadas não vive na mesma cidade em que os pesquisadores e por proporcionar maior controle da linha de questionamento - conforme descrito no item Coleta de Dados. A entrevista teve questões abertas com objetivo de suscitar concepções e opiniões das participantes.

\subsection{Coleta de Dados}

Para a pesquisa de campo entrou-se em contato com duas intérpretes e tradutoras da Língua Brasileira de Sinais. A primeira delas reside na cidade de Porto Alegre e a segunda mora em São Vicente, assim, obtiveram-se pontos de vista de duas regiões distintas sobre o tema. A entrevista foi construída com 10 perguntas respondidas via e-mail de forma aberta, baseadas nos estudos realizados durante o levantamento teórico e tratam da mediação do tradutor e intérprete de Libras com o aluno surdo, da relação com o Professor e com os 
colegas, das limitações e aprendizado, do conhecimento e compreensão do português escrito, entre outros.

Tabela 01 - Entrevistas realizadas de modo digital

\begin{tabular}{|c|c|c|}
\hline Perguntas & Entrevista 1 - Porto Alegre & Entrevista 2 - São Vicente \\
\hline $\begin{array}{l}\text { 1. Há quanto tempo você é } \\
\text { Intérprete/Tradutor de Libras? }\end{array}$ & Oficialmente a mais ou menos 4 anos. & Há 6 anos. \\
\hline $\begin{array}{l}\text { 2. Como teve início a sua relação com } \\
\text { a Língua Brasileira de Sinais? }\end{array}$ & $\begin{array}{c}\text { Eu queria ajudar as pessoas e sempre que } \\
\text { via um surdo tentando se comunicar } \\
\text { percebia sua dificuldade. Então procurei } \\
\text { alguns cursos para iniciar o aprendizado } \\
\text { da Língua. }\end{array}$ & $\begin{array}{l}\text { Comecei a querer me dedicar porque } \\
\text { meus pais são deficientes auditivos. }\end{array}$ \\
\hline $\begin{array}{l}\text { 3. Você acredita que sua profissão é } \\
\text { reconhecida atualmente? Justifique } \\
\text { sua resposta. }\end{array}$ & $\begin{array}{l}\text { Acredito que ainda temos uma longa } \\
\text { jornada pela frente, mas já demos um } \\
\text { grande passo com a lei do Intérprete de } \\
\text { Libras. Não temos um sindicato o que } \\
\text { dificulta um pouco as conquistas, mas } \\
\text { estamos nos encaminhando. }\end{array}$ & $\begin{array}{l}\text { Acredito que não é muito reconhecida } \\
\text { porque são poucos os lugares que exigem } \\
\text { Intérpretes. }\end{array}$ \\
\hline $\begin{array}{l}\text { 4. Como se dá a mediação do } \\
\text { aprendizado entre o Intérprete de } \\
\text { Libras, o aluno e o Professor de } \\
\text { determinada disciplina? }\end{array}$ & $\begin{array}{c}\text { No geral o intérprete apenas interpreta o } \\
\text { que é dito pelo professor, porém } \\
\text { infelizmente somos humanos e } \\
\text { percebemos que com apenas } \\
\text { interpretação o aluno terá dificuldades. } \\
\text { Existem professores que se esforçam, } \\
\text { trazem um conteúdo adaptado, } \\
\text { encaminham antes da aula para que o } \\
\text { aluno acompanhe com maior facilidade, } \\
\text { mas também temos aqueles professores } \\
\text { que fazem apenas seu trabalho, pois } \\
\text { acreditam que o aluno deverá correr atrás } \\
\text { e ter um esforço maior. }\end{array}$ & $\begin{array}{l}\text { Temos que começar a aprendizagem e o } \\
\text { conhecimento do ensino básico no início. } \\
\text { Proporcionar tranquilidade, paciência e } \\
\text { segurança ao aluno. }\end{array}$ \\
\hline $\begin{array}{l}\text { 5. Como é a interação/integração entre } \\
\text { o estudante com deficiência auditiva e } \\
\text { o Professor em sala de aula? O mesmo } \\
\text { consegue tirar suas dúvidas com o } \\
\text { Professor, através da mediação do } \\
\text { Intérprete? Justifique. }\end{array}$ & $\begin{array}{l}\text { O aluno é extremamente independente, } \\
\text { ele é exatamente igual a um ouvinte } \\
\text { porém existe a limitação, que no caso é a } \\
\text { surdez. Nós Intérpretes somos a voz e os } \\
\text { ouvidos do aluno, estamos ali para } \\
\text { facilitar. Ele pode e deve fazer } \\
\text { questionamentos, assim como em } \\
\text { apresentações de trabalho eu oralizo ele e } \\
\text { flui uma comunicação normal. }\end{array}$ & $\begin{array}{l}\text { Tem sim um Intérprete, pois há } \\
\text { dificuldades de conhecimentos sobre as } \\
\text { aulas. Até mesmo em uma pergunta } \\
\text { simples que pode não ser interpretada } \\
\text { pelo professor. }\end{array}$ \\
\hline $\begin{array}{l}\text { 6. Como é a interação/integração entre } \\
\text { o estudante com deficiência auditiva e } \\
\text { os demais colegas de turma? }\end{array}$ & $\begin{array}{l}\text { Isso vai muito de cada aluno, no meu } \\
\text { caso por exemplo eu prezo muito meu } \\
\text { intervalo sozinha, para descansar a } \\
\text { cabeça e retomar forças para o segundo }\end{array}$ & $\begin{array}{l}\text { Muito preconceito, as vezes, e uns até } \\
\text { tentam aprender. Mas hoje em dia não há } \\
\text { muito interesse em entender e nem }\end{array}$ \\
\hline
\end{tabular}




\begin{tabular}{|c|c|c|}
\hline & $\begin{array}{c}\text { momento da aula. A aluna que estou } \\
\text { acompanhando no momento, durante o } \\
\text { intervalo pega um papel e escreve para } \\
\text { os colegas, existe uma comunicação e } \\
\text { conversas bem legais, ela também tem } \\
\text { uma certa facilidade para ler lábios, que } \\
\text { ajuda bastante. }\end{array}$ & participar dessa interação. \\
\hline $\begin{array}{l}\text { 7. O estudante com deficiência } \\
\text { auditiva lê textos em aula, somente } \\
\text { mediante auxílio do Intérprete ou de } \\
\text { forma autônoma? Um panorama geral } \\
\text { dos alunos que você orienta. }\end{array}$ & $\begin{array}{l}\text { Existem vários tipos de surdos, alguns } \\
\text { com uma facilidade enorme com o } \\
\text { português e outros que têm muita } \\
\text { dificuldade para entender. A maioria tem } \\
\text { autonomia de ler sozinhos e se não } \\
\text { compreendem alguma palavra eu explico } \\
\text { ou peço auxílio do professor. }\end{array}$ & $\begin{array}{l}\text { Depende, a maioria consegue ler } \\
\text { sozinho. Mas ainda assim, chamam pra } \\
\text { tirar dúvidas, como por exemplo, } \\
\text { perguntar se está correto o texto lido, } \\
\text { entre outras. }\end{array}$ \\
\hline $\begin{array}{l}\text { 8. O aluno com deficiência auditiva } \\
\text { consegue resolver com autonomia } \\
\text { exercícios/provas? Como é realizada a } \\
\text { mediação do estudante com o } \\
\text { Intérprete nesse momento? }\end{array}$ & $\begin{array}{c}\text { Olha, no momento de provas, exercícios } \\
\text { e trabalhos o Intérprete geralmente se } \\
\text { afasta e apenas auxilia naquilo que lhe é } \\
\text { solicitado. No caso de dúvidas em } \\
\text { relação a alguma coisa de prova por } \\
\text { exemplo eu chamo o professor e peço } \\
\text { que ele fale para que eu traduza para o } \\
\text { aluno, assim evita suspeitas de cola ou } \\
\text { até mesmo que o aluno solicite alguma } \\
\text { resposta. }\end{array}$ & \\
\hline $\begin{array}{l}\text { 9. A escola/universidade que você } \\
\text { trabalha prioriza a inclusão dos } \\
\text { estudantes com deficiência auditiva? } \\
\text { Se sim, quais são as principais ações } \\
\text { realizadas para que ela ocorra? }\end{array}$ & $\begin{array}{c}\text { A faculdade que eu trabalho se preparou } \\
\text { antes para receber um aluno, } \\
\text { questionaram quais adaptações que } \\
\text { deveriam fazer e informaram aos colegas } \\
\text { como deveriam proceder, mas no geral } \\
\text { não há nenhum tipo de ação sendo feita } \\
\text { periodicamente, por exemplo, Até } \\
\text { mesmo porque os alunos e colegas já } \\
\text { estão acostumados e se há algum } \\
\text { impasse se resolve junto a coordenadoria } \\
\text { do curso. }\end{array}$ & $\begin{array}{l}\text { Sim, porque é muito importante no } \\
\text { aprendizado. Incentivamos até demais a } \\
\text { ter um dialogo em Libras. Temos até } \\
\text { uma sala de aula própria para dar aula, } \\
\text { específica sobre a Linguagem Brasileira } \\
\text { de Sinais. }\end{array}$ \\
\hline $\begin{array}{l}10 . \text { Você teria alguma } \\
\text { sugestão/melhoria sobre a } \\
\text { integração/mediação em sala de aula } \\
\text { entre aluno com deficiência auditiva, } \\
\text { Professor, Intérprete e demais colegas } \\
\text { de classe? }\end{array}$ & $\begin{array}{c}\text { Bah, existe ainda muito medo por parte } \\
\text { das demais pessoas, acho que às vezes } \\
\text { vinculam a deficiência auditiva a mais } \\
\text { algum outro tipo, porque sempre sou } \\
\text { questionada da capacidade do aluno, } \\
\text { enquanto que na realidade eles tem as } \\
\text { mesmas se não mais. Existem por } \\
\text { exemplo surdos com QI altíssimo, eles } \\
\text { são focados e mega inteligentes. Faltam } \\
\text { informações e principalmente empatia } \\
\text { das pessoas. }\end{array}$ & $\begin{array}{c}\text { Sim. É importante para o aprendizado } \\
\text { unirmos tanto o deficiente quantos os } \\
\text { demais. Fazermos palestras e ter maiores } \\
\text { diálogos sobre o assunto. Campanhas } \\
\text { demonstrando o quanto é importante o } \\
\text { apoio do Governo e Estado. Tornar } \\
\text { obrigatório a presença de Intérpretes nas } \\
\text { salas de aula. }\end{array}$ \\
\hline
\end{tabular}

Fonte: Elaborado pela autora a partir das Entrevistas realizadas, 2016. 
Como pôde ser notado, a partir das entrevistas, é possível perceber que em alguns momentos as duas regiões, onde residem as intérpretes (Porto Alegre e São Vicente) se parecem bastante. Como por exemplo, as duas entrevistadas acreditam que a profissão de tradutor e intérprete de Libras ainda não é muito reconhecida no Brasil, na questão de o estudante com deficiência auditiva ter autonomia na leitura e só pedir auxílio para ter certeza do que foi lido e também a respeito das Instituições de Ensino na qual trabalham, ao afirmarem que as mesmas investem na inclusão dos alunos com deficiência auditiva.

Nas demais questões elas divergem um pouco nas respostas, mas em um panorama geral pode-se identificar, a partir das entrevistas, que o estudante com deficiência auditiva necessita de modo fundamental da mediação com o tradutor e intérprete em Libras, para poder se comunicar/tirar dúvidas com o professor e interagir com os colegas. Entende-se assim, que essa interação para o aluno surdo, é muito importante, pois auxilia no desenvolvimento acadêmico, pessoal e também na autoestima dele.

\section{CONSIDERAÇÕES}

Este artigo possibilitou a compreensão de conceitos relacionados aos estudantes com deficiências auditivas no Ensino Superior no Brasil e demonstrou como o design universal e a tecnologia assistiva, podem se tornar aliadas no desenvolvimento dos alunos surdos e importantes ferramentas no auxílio à inclusão acadêmica. A partir da revisão teórica, a elaboração das perguntas para a entrevista foi facilitada, trazendo maior entendimento sobre a temática do estudo para os pesquisadores.

A pesquisa mostrou dados relevantes sobre a deficiência no Brasil, principalmente, com relação a Educação Superior e trouxe à tona a importância da Língua Brasileira de Sinais para os surdos como primeira língua. Assim, pode-se perceber que a comunicação humana é essencial para todos os seres humanos e não pode ser direito de apenas uma porcentagem da população.

Durante o estudo se evidenciou que o acesso ao conhecimento e ao Ensino Superior de qualidade é um direito, que independente das diferenças, deve ser garantido a todos os estudantes universitários. 
Também foi possível entender sobre os conceitos de mediação, a partir de Vygotsky, relacionando-o com os indivíduos envolvidos no processo de aquisição do conhecimento do aluno surdo como, por exemplo: os professores, tradutores e intérpretes de Libras, os colegas de aula, entre outros. Assim, pode-se compreender que para que a relação educativa possa se constituir é preciso que se desenvolvam mediações, como potencializadoras da capacidade interativa entre as pessoas.

A partir das entrevistas, pode-se identificar, sob o olhar de profissionais atuantes na área da inclusão, o cotidiano e a experiência de profissionais tradutoras e intérpretes de Libras, os seus anseios, suas opiniões, sugestões de possíveis avanços e também como se dá a mediação entre elas e os estudantes surdos.

Chegou-se à conclusão de que as leis e decretos por si só não bastam para a inclusão dos alunos surdos, as Instituições de Ensino, necessitam dar condições aos estudantes e também trabalhar a mudança de paradigmas antigos quanto à deficiência, respeitando o acesso à informação por meio da Libras.

\section{REFERÊNCIAS}

ANDRADE, M. S. A. et.al. Pessoas com deficiência rumo ao processo de inclusão na educação superior. Revista Digital de Pesquisa CONQUER da Faculdade São Francisco de Barreiras, vol. $1,2007$.

BERSCH, Rita. Tecnologia Assistiva. Brasil, 2016. Disponível na internet por http em: $<\mathrm{http}: / /$ www.assistiva.com.br/tassistiva.html>. Acesso em 23 set. 2016.

BERSCH, Rita. Introdução a Tecnologia Assistiva. Porto Alegre: Assistiva, Tecnologia e Educação, 2013.

BITTENCOURT, L. S. et. al. Acessibilidade e Cidadania: barreiras arquitetônicas e exclusão social dos portadores de deficiência física. Anais do $2^{\circ}$ Congresso Brasileiro de Extensão Universitária, 2, Belo Horizonte, 2004. Belo Horizonte, 2004.

BRASIL. Decreto $\mathbf{n}^{0} 5.296$ de 02 de dezembro de 2004. Regulamenta as Leis nos 10.048 , de 8 de novembro de 2000, que dá prioridade de atendimento às pessoas que especifica, e 10.098, de 19 de dezembro de 2000, que estabelece normas gerais e critérios básicos para a promoção da acessibilidade das pessoas com deficiência ou com mobilidade reduzida, e dá outras providências. Disponível em: $<$ http://www.planalto.gov.br/ccivil_03/_ato2004-2006/2004/decreto/d5296.htm>. Acesso dia: 25 de out. de 2016.

BRASIL. Lei $\mathbf{n}^{0} .10098$ de 19 de dezembro de 2000. Estabelece normas gerais e critérios básicos 
para a promoção da acessibilidade das pessoas com deficiência ou com mobilidade reduzida, e dá outras providências. Disponível em: <http://www.planalto.gov.br/ccivil_03/leis/L10098.htm>. Acesso dia: 25 de out. de 2016.

BRASIL. Lei $\mathbf{n}^{\mathbf{0}}$. 10.436, de 4 de abril de 2002. Dispõe sobre a Língua Brasileira de Sinais - Libras e dá outras providências. Disponível em: $<$ http://www.planalto.gov.br/ccivil_03/leis/2002/110436.htm>. Acesso dia: 25 de out. de 2016.

BRASIL. Lei $\mathbf{n}^{0}$. 13.146 de 06 de julho de 2015. Institui a Lei Brasileira de Inclusão da Pessoa com Deficiência (Estatuto da Pessoa com Deficiência). Disponível em: $<$ http://www.planalto.gov.br/ccivil_03/_ato2015-2018/2015/lei/113146.htm>. Acesso dia: 25 de out. de 2016.

CAMBIAGHI, Silvana. Desenho Universal: métodos e técnicas para arquitetos e urbanistas. São Paulo: Editora Senac São Paulo, 2007.

CARLETTO, Ana Claudia; CAMBIAGHI, Silvana. Desenho Universal: um conceito para todos. São Paulo: Instituto Mara Gabrilli, 2008.

Cartilha do Censo 2010 - Pessoas com Deficiência. Secretaria de Direitos Humanos da Presidência - SDH/PR; Secretaria Nacional de Promoção dos Direitos da Pessoa com Deficiência - SNPD. Brasília: SDH-PR/SNPD, 2012.

COOK, A.M; HUSSEY, S. M. Assistive Tecnologies: Principles and Pratice, Mosby - Year Book, USA-Missouri, 1995.

CRESWELL, J. W. Projeto de pesquisa: métodos qualitativo, quantitativo e misto. Porto Alegre: Artmed, 2010.

Declaração Universal dos Direitos Humanos. Centro de Informação das Nações Unidas Rio de Janeiro (UNIC/Rio/005). Rio de Janeiro, 2009. Disponível em: < http://www.onu.org.br/img/2014/09/DUDH.pdf>. Acesso dia 30 de out. de 2016.

DEMO, Pedro. Educar pela pesquisa. 9 ed. Campinas, SP: Autores Associados, 2011.

FENEIS. LIBRAS: língua brasileira de sinais. Belo Horizonte: s. ed.1995.

FRIÃES, H. S; PEREIRA, M. C. C. Compreensão da leitura e surdez. In: LACERDA, C. B. F. de; GÓES, M. C. R. de. Surdez: processos educativos e subjetividade. São Paulo: Lovise, 2000. p.113122.

GUIA sobre a Lei Brasileira da Inclusão (LBI 13.146/15). Brasília, Mara Gabrilli. 2015. Disponível em: < http://maragabrilli.com.br/wp-content/uploads/2016/03/Guia-sobre-a-LBI-digital.pdf $>$. Acesso dia: 24 de out. de 2016.

IIDA, Itiro. Ergonomia: projeto e produção. $2^{\text {a }}$ edição revisada e ampliada - São Paulo: Blucher, 2005.

INCLUIR - Núcleo de Inclusão e Acessibilidade. Disponível em: $<$ http://www.ufrgs.br/incluir/servicos-oferecidos-1/copy_of_servicos-oferecidos $>$. Acesso dia: $31 \mathrm{de}$ out. de 2016.

LAMÔNICA, D. A. C et al. Acessibilidade em ambiente universitário: identificação de barreiras 
arquitetônicas no campus da USP de Bauru. Revista Brasileira de Educação Especial. v.14, n.2, p. 177-188, 2008.

LOPES, Maura Corcini; VEIGA-NETO, Alfredo. Marcadores culturais surdos: quando eles se constituem no espaço escolar. Perspectiva, v. 24, n. especial. Florianópolis: UFSC, 2006.

LOPES, Maura Corcini. Surdez \& Educação. Belo Horizonte: Autêntica, 2007.

PRODANOV, Cleber Cristiano; ERNANI, Cesar de Freitas. Metodologia do trabalho científico: métodos e técnicas da pesquisa e do trabalho acadêmico. 2. ed. - Novo Hamburgo: Feevale, 2013.

QUADROS, R. M. Educação de surdos: a aquisição da linguagem. Porto Alegre: Artmed, 1997.

QUADROS, R. M. O tradutor e intérprete de língua brasileira de sinais e língua portuguesa. Secretaria de Educação Especial; Programa Nacional de Apoio à Educação de Surdos - Brasília: MEC; SEESP, 2004.

SÁ, Nídia Regina Limeira de. Cultura, poder e educação de surdos. São Paulo: Paulinas, 2006.

SAMPIERI, Roberto Hernandez; COLLADO, Carlos Fernández; LUCIO, María del Pilar Baptista. Metodologia de Pesquisa. Porto Alegre: Ed. Penso, 2013.

SILVA, Tomaz Tadeu. A política e a epistemologia do corpo normalizado. Revista Espaço. Rio de Janeiro, 1997.

SILVEIRA, A. L. M. O interacionismo social: Lev Vygotsky. Porto Alegre: Material de aula, 2016.

TAILlE, Y.; OLIVEIRA, M. K.; DANTAS, H. Piaget, Vygotsky, Wallon: Teorias Psicogenéticas em discussão. São Paulo: Summus, 1992.

ZANELLA, Andréa Vieira. Vygotsky e o conceito de "Zona de desenvolvimento proximal". Itajai: Univali, 2007.

Recebido em 29 de dezembro 2016 Aprovado em 8 maio de 2017 